
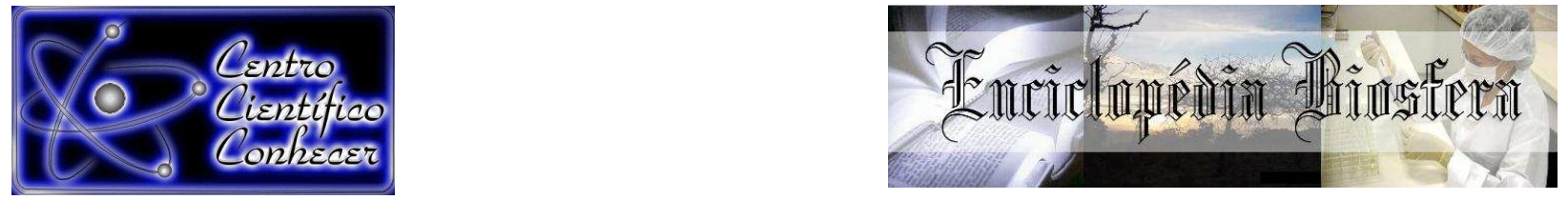

\title{
CARACTERIZAÇÃO FíSICA E FÍSICO-QUÍMICA DE TOMATES ORGÂNICOS UTILIZANDO DIFERENTES COMPOSTOS
}

\author{
Mairla Nascimento de Lacerda ${ }^{1}$, Bruno Layson Sousa do Vale ${ }^{2}$, Adriano da Silva \\ Almeida $^{3}$, Mauro Sérgio Teodoro ${ }^{4}$, Valdinar Bezerra dos Santos ${ }^{5}$ \\ ${ }^{1}$ Eng.Agrônoma pela Universidade Estadual do Piauí (mairllaphb@hotmail.com) \\ Parnaíba- Brasil. \\ ${ }^{2}$ Eng.Agrônomo pela Universidade Estadual do Piauí. Parnaíba- Brasil. \\ ${ }^{3}$ Professor Doutor da Universidade Estadual do Piauí, Parnaíba- Brasil \\ ${ }^{4}$ Eng.Agrônomo, Analista Embrapa Meio-Norte,Parnaíba- Brasil. \\ ${ }^{5}$ Professor Doutor da Universidade Estadual do Piauí, Parnaíba- Brasil.
}

Recebido em: 03/10/2016 - Aprovado em: 21/11/2016 - Publicado em: 05/12/2016 DOI: 10.18677/EnciBio_2016B_021

\begin{abstract}
RESUMO
O tomate (Lycopersicum esculentum Mill.) é uma das olerícolas mais cultivadas no Brasil e no mundo sob diferentes sistemas de manejo. O presente trabalho objetivou avaliar as características físicas e físico-químicas de tomates produzidos em área experimental na Embrapa Meio-Norte, utilizando diferentes compostos orgânicos. O ensaio foi desenvolvido durante o período de maio a outubro de 2013, sendo analisados frutos de tomateiro híbrido do tipo Caqui, destinado ao consumo in natura ou mesa. Nas análises físicas e físico-químicas foram determinados peso dos frutos, comprimento e diâmetro, teor de vitamina $\mathrm{C}$, acidez total titulável (ATT), sólidos solúveis totais (SST), pH e relação sólidos solúveis/acidez titulável (SS/AT). O experimento foi conduzido em delineamento inteiramente casualizado, composto de seis tratamentos e quatro repetições, sendo a unidade experimental constituída por vinte e quatro frutos. Em geral os resultados demonstraram que os tomates orgânicos apresentaram padrões de qualidade para o consumo in natura e homogeneidade quanto às características físicas e físico-químicas analisadas
\end{abstract}

PALAVRAS-CHAVE: Manejo orgânico. Qualidade. Sólidos solúveis totais.

\section{PHYSICAL AND PHYSICOCHEMICAL CHARACTERIZATION OF ORGANIC TOMATOES USING DIFFERENT COMPOUNDS}

\begin{abstract}
The tomato (Lycopersicum esculentum Mill.) is one of the most cultivated vegetable crops in Brazil and around the world under different management systems. The tomato organic farming is a relatively difficult task, but researches have shown positive results related to the management and obtainment of fruits with commercial quality. This study aimed to evaluate the physical and physicochemical characteristics of tomatoes produced in the experimental area at Embrapa MeioNorte, using different organic compounds. The test was developed in a greenhouse during the period from May to October, 2013, being analyzed tomato fruits of type Persimmons, destined for fresh or table consumption. In the physical and
\end{abstract}


physicochemical analyzes were determined the weight, length and diameter of tomato fruits, and also $\mathrm{C}$ vitamin content, total tritatable acidity (ATT), total soluble solids (SST), $\mathrm{pH}$ and relation soluble solids/titratable acidity (SS/ AT). The experiment was conducted in a completely randomized design with six treatments and four replications, and the experimental unit consisting of twenty-four fruits. In general, the results showed that organic tomatoes had quality standards for fresh consumption and homogeneity concerning to the physical and physicochemical characteristics analyzed.

KEYWORDS: Organic management. Quality. Total soluble solids.

\section{INTRODUÇÃO}

O cultivo orgânico de tomateiro (Lycopersicum esculentum Mill.) é uma tarefa relativamente difícil uma vez que o tomate é uma hortaliça muito exigente quanto ao clima, solo e tratos culturais. Porém as pesquisas têm aumentado bastante e os resultados mostram avanços na condução da cultura, na obtenção de frutos de excelente produtividade e qualidade, capazes de competir no mercado de hortaliças (LEAL, 2006; GONÇALVES, 2010). A qualidade dos produtos orgânicos corresponde ao conjunto de atributos ou propriedades que os tornam apreciados como alimentos e tão importantes na dieta humana (ALVARENGA, 2013).

Dentre os atributos mais importantes relacionados à qualidade e preferência de consumo de tomate, está a aparência, o sabor, o aroma, a textura, a cor, a firmeza dos frutos, a perda de peso, as substâncias antioxidantes presentes no tomate como licopeno, xantofilas e carotenoides, e o valor nutricional, baseado principalmente no conteúdo de vitaminas e minerais (CHITARRA \& CHITARRA 2005; ALVARENGA, 2013). Estas características sofrem influência das condições edafoclimáticas, cultivar, época e local de colheita, tratos culturais e tratamento póscolheita, variando segundo o destino do fruto e das exigências do mercado consumidor (FAGUNDES \& YAMANISHI, 2001).

Tendo em vista os diversos fatores que podem alterar a qualidade dos tomates e considerando a crescente demanda por alimentos orgânicos, objetivou-se avaliar as características físicas e físico-químicas de tomates produzidos em área experimental na Embrapa Meio-Norte, utilizando-se diferentes compostos orgânicos.

\section{MATERIAL E MÉTODOS}

O ensaio foi desenvolvido durante o período de maio a outubro de 2013, em área experimental da Embrapa meio-norte, unidade de Execução e Pesquisa da cidade de Parnaíba-Piauí (0305' S; 41946' W e 46,8 m). O clima da região de acordo com a classificação de Koppen, é do tipo AW' tropical chuvoso com umidade relativa do ar média anual de $74,9 \%$, temperatura média do ar de $27,9^{\circ} \mathrm{C}$, evapotranspiração de referência média de $5,4 \mathrm{~mm}$ e precipitação média anual de $965 \mathrm{~mm}$, porém concentradas de janeiro a maio (BASTOS et al., 2000).

Foram analisados frutos de tomateiro (Lycopersicon esculentum Mill.) cultivar Santa Cruz produzidos em casa de vegetação sob manejo orgânico na área experimental da Embrapa Meio-Norte cidade de Parnaíba, destinados ao consumo in natura ou mesa. Para a produção do tomateiro orgânico utilizou-se na adubação diferentes compostos orgânicos totalizando cinco tratamentos: T1 - Guandu folha larga; T2 - Crotalária juncea; T3 - Leucena; T4 - Gliricídia; T5 - Mucuna preta. Avaliou-se também frutos de tomateiro cultivados sob manejo convencional 
adquiridos em mercado municipal da região. A composição química dos tratamentos orgânicos encontra-se na Tabela 1.

TABELA 1 - Resultados analíticos dos compostos orgânicos, Parnaíba - PI 2013.

\begin{tabular}{lcccc}
\hline COMPOSTO & Relação C/N & $\mathrm{P}(\mathrm{g} / \mathrm{kg})$ & $\mathrm{K}(\mathrm{mg} / \mathrm{kg})$ & $\mathrm{Ca}(\mathrm{g} / \mathrm{kg})$ \\
\hline Guandu folha larga & 12,89 & 5,3 & 5452 & 9,7 \\
Crotalária juncea & 10,51 & 5,6 & 5447 & 9,6 \\
Leucena & 12,23 & 6,0 & 5199 & 13,3 \\
Glirić́dia & 11,25 & 8,1 & 4950 & 13,7 \\
Mucuna preta & 10,63 & 6,5 & 5197 & 10,9 \\
\hline
\end{tabular}

O delineamento experimental utilizado foi inteiramente casualizado contendo seis tratamentos e quatro repetições para as análises físicas e físico-químicas , sendo a unidade experimental constituída por 24 frutos. Os resultados foram submetidos a análise de variância utilizando o programa ASSISTAT, versão 7.7 (SILVA \& AZEVEDO, 2002). Quando constatada significância entre os tratamentos, foi realizado o teste Tukey a $5 \%$ de probabilidade para a comparação das médias.

A coleta dos frutos de tomateiro teve inicio no mês de agosto do ano de 2013, em estádio maduro. Para cada tratamento foram colhidos quatro frutos de forma aleatória em cada parcela. Após a colheita dos frutos, estes foram acondicionados em sacos plásticos e conduzidos ao laboratório de Química da Universidade Estadual do Piauí - UESPI, Campus Alexandre Alves de Oliveira.

No laboratório os frutos foram submetidos a análises físicas (peso dos frutos, comprimento e diâmetro) e posteriormente processados, sendo então obtido o suco utilizado na caracterização físico-química. As análises físico-químicas avaliadas foram: teor de vitamina $\mathrm{C}, \mathrm{pH}$, acidez total titulável, sólidos solúveis totais, relação Sólidos solúveis/Acidez total titulável.

\section{Comprimento e diâmetro basal}

O comprimento e o diâmetro dos frutos foi mensurado com o uso de paquímetro digital (Pantec $300 \mathrm{~mm}$ ) e expresso em milímetros.

\section{Peso dos frutos}

Utilizando-se balança semi-analítica, o peso total dos frutos foi determinado com os resultados expressos em gramas.

\section{Determinação do pH}

O potencial hidrogeniônico foi medido diretamente na polpa, logo após processamento, utilizando-se um potenciômetro digital (Tecnal 3MP) com membrana de vidro conforme AOAC (1995), aferido com tampões de pH 4 e 7.

\section{Teor de vitamina $\mathbf{C}$}

O teor de vitamina $C(\mathrm{mg} / 100 \mathrm{~g})$ por meio de titulação com solução de DFI (2,6-dicloro-fenol-indofenol $0,02 \%$ ) até coloração levemente rósea, utilizando-se uma alíquota de $4 \mathrm{~mL}$ proveniente de $5 \mathrm{~g}$ de polpa diluída em $50 \mathrm{~mL}$ de ácido oxálico a $0,5 \%$ de acordo com STROHECKER \& HENNING (1967). 


\section{Sólidos Solúveis Totais (SST)}

De acordo com a metodologia recomendada pelo AOAC (1995), após filtração da polpa em papel filtro, a leitura foi expressa em Brix utilizando refratômetro digital de marca Atago PR-101 com escala variando de 0 - 45 Brix.

\section{Acidez Total Titulável (ATT)}

Foi obtida diluindo-se $1 \mathrm{~g}$ de polpa em $50 \mathrm{~mL}$ de água destilada em solução de $\mathrm{NaOH}(0,1 \mathrm{~N})$ e expressa em percentagem de ácido cítrico, segundo metodologia do IAL (1985).

\section{Relação SS/AT}

A relação SS/AT foi obtida através do quociente entre sólidos solúveis totais e acidez titulável (BRASIL, 2005).

\section{RESULTADOS E DISCUSSÃO}

As diferenças na qualidade física dos frutos podem ser observadas por meio dos valores médios encontrados para as variáveis (peso dos frutos, comprimento e diâmetro basal) dos seis tratamentos apresentados na Tabela 2.

TABELA 2- Características físicas de tomates Santa Cruz em cultivo orgânico e convencional, Parnaíba - PI 2013.

\begin{tabular}{|c|c|c|c|}
\hline Tratamentos & $\begin{array}{l}\text { Peso } \\
\text { (g) }\end{array}$ & $\begin{array}{l}\text { Comprimento } \\
(\mathrm{cm})\end{array}$ & $\begin{array}{l}\text { Diâmetro basal } \\
(\mathrm{cm})\end{array}$ \\
\hline T0 & $115,9 a$ & $4,95 \mathrm{c}$ & $6,24 \mathrm{a}$ \\
\hline T1 & $112,4 \mathrm{a}$ & $5,48 \mathrm{ab}$ & $6,12 \mathrm{a}$ \\
\hline T2 & $119,6 \mathrm{a}$ & $5,56 \mathrm{a}$ & $6,21 \mathrm{a}$ \\
\hline T3 & $115,4 \mathrm{a}$ & $5,38 \mathrm{ab}$ & $6,18 \mathrm{a}$ \\
\hline T4 & $114,7 \mathrm{a}$ & $5,39 a b$ & $6,11 \mathrm{a}$ \\
\hline T5 & $100,8 \mathrm{a}$ & $5,18 \mathrm{bc}$ & $5.91 \mathrm{a}$ \\
\hline
\end{tabular}

Médias seguidas da mesma letra na coluna, não diferem significativamente entre si $(p>0,05)$ pelo teste de Tukey.

Quanto ao peso dos frutos (PF), a amplitude de variação encontrada para os tratamentos em cultivo orgânico ficou entre 100,80 e 119,62g, não diferindo estatisticamente do cultivo convencional que obteve uma média de $115,92 \mathrm{~g}$ de peso do fruto. Comparando os valores de PF encontrados, verifica-se que os frutos possuem pesos médios similares aos encontrados por PEIXOTO et al. (1999), que ao analisarem tomates do tipo Santa Cruz, obteve valores médios superiores a $112 \mathrm{~g}$ em $79 \%$ dos frutos amostrados.

Sabe-se que o peso de tomates é uma característica relevante para a indústria uma vez que está relacionado ao rendimento (ROSA et al., 2011). De acordo com ALVARENGA (2013) tomates do tipo Santa Cruz apresentam peso médio variando de 80 a $200 \mathrm{~g}$, portanto os frutos orgânicos apresentados no presente trabalho se enquadram neste padrão.

Quanto ao comprimento dos frutos os tratamentos T1, T2, T3 e T4 do cultivo orgânico apresentaram-se mais compridos não diferindo $(p>0,05)$ entre si. $O$ comprimento desses frutos variou de 5,38 a $5,56 \mathrm{~cm}$, diferindo de T0 e T5 que obtiveram valores estatisticamente iguais, porém inferiores aos demais tratamentos, com valores de 4,95 e $5,18 \mathrm{~mm}$, respectivamente. Valores diferentes foram 
encontrados por MACHADO NETO (2014), que obtiveram médias de 6,34 e 6,86 cm para tomates de mesa em cultivo convencional e comprimento de 6,48 e 6,84 para cultivo orgânico. ALVARENGA (2004) declarou valores de 6 a $8 \mathrm{~cm}$ para frutos do grupo Santa Cruz. Nenhum dos tratamentos analisados neste trabalho obtiveram frutos com este padrão de comprimento.

Avaliando-se o diâmetro basal dos frutos não foi constatada diferença significativa entre os tratamentos orgânico e convencional, variando de 5,91 a $6,24 \mathrm{~cm}$. Valores semelhantes foram por BRITO JUNIOR (2012) que na avaliação de cinco cultivares de tomates produzidos em casa de vegetação observou diâmetros médios entre 5,13 e $6,58 \mathrm{~cm}$. Ao contrário do que ocorreu com o comprimento, os frutos apresentaram baixa variação quanto ao diâmetro basal. Os resultados das variáveis físico-químicas dos frutos são apresentados na Tabela 3. Essas variáveis são indicadoras das características sensoriais, importantes tanto para industrialização, quanto para o consumo in natura.

TABELA 3- Valores médios das características físico-químicas em tomates cultivados sob sistema orgânico e convencional de produção em diferentes tratamentos, Parnaíba - PI 2013.

\begin{tabular}{lcrrrr}
\hline Tratamento & $\begin{array}{l}\text { Vitamina C } \\
\text { (mg/100g) }\end{array}$ & $\mathrm{pH}$ & $\begin{array}{l}\text { SST } \\
\text { (Brix) }\end{array}$ & $\begin{array}{l}\text { ATT } \\
\text { (\%de ácido } \\
\text { cítrico) }\end{array}$ & SS/AT \\
\hline T0 & $15,69 \mathrm{c}$ & $4,41 \mathrm{a}$ & $4,75 \mathrm{a}$ & $0,38 \mathrm{a}$ & $12,42 \mathrm{~b}$ \\
T1 & $20,76 \mathrm{ab}$ & $4,47 \mathrm{a}$ & $3,92 \mathrm{~b}$ & $0,24 \mathrm{~b}$ & $16,11 \mathrm{ab}$ \\
T2 & $22,61 \mathrm{a}$ & $4,50 \mathrm{a}$ & $3,85 \mathrm{~b}$ & $0,22 \mathrm{~b}$ & $17,27 \mathrm{a}$ \\
T3 & $20,10 \mathrm{ab}$ & $4,45 \mathrm{a}$ & $3,85 \mathrm{~b}$ & $0,23 \mathrm{~b}$ & $16,25 \mathrm{ab}$ \\
T4 & $20,49 \mathrm{ab}$ & $4,47 \mathrm{a}$ & $3,95 \mathrm{~b}$ & $0,23 \mathrm{~b}$ & $17,11 \mathrm{a}$ \\
T5 & $18,64 \mathrm{bc}$ & $4,46 \mathrm{a}$ & $3,77 \mathrm{~b}$ & $0,24 \mathrm{~b}$ & $15,70 \mathrm{ab}$ \\
\hline
\end{tabular}

Médias seguidas da mesma letra na coluna, não diferem significativamente entre si $(p>0,05)$ pelo teste de Tukey.

Os teores de vitamina $C$ obtidos neste ensaio apresentaram variações médias de 15,69 a 22,61 mg/100g entre os tratamentos observados. Esses resultados foram superiores aos teores de vitamina $C$ encontrados por FERREIRA et al. (2012), que obtiveram médias de 13,43 a 15,38 mg/100g de frutos e por PAULA et al. (2015) que em cultivo convencional de híbridos de tomateiro verificaram valores de 12,32 $\mathrm{mg} / 100$ e $15,71 \mathrm{mg} / 100 \mathrm{~g}$. Resultados próximos aos obtidos neste trabalho foram encontrados por ROCHA \& SILVA (2011), com valores respectivos para tomates convencional e orgânico de 14,77 e 18,16 mg/100g.

A testemunha apresentou resultado inferior $(15,69 \mathrm{mg} / 100 \mathrm{~g})$, diferindo estatisticamente dos demais tratamentos, com exceção do $T 5$, onde não foi observada diferença significativa. De acordo com ROCHA \& SILVA (2011), essas diferenças podem ser decorrentes de fatores que devem ser considerados, como condições climáticas, manejo e sistema de cultivo que podem influenciar nas quantidades presentes de vitamina $\mathrm{C}$.

Para o conteúdo da acidez total titulável (ATT), os frutos orgânicos demonstraram os menores valores entre 0,22 e 0,24\%, não apresentando diferenças estatísticas entre si, entretanto a testemunha apresentou valor de acidez significativamente superior $(0,38 \%)$ em relação aos demais tratamentos. 
Resultados de acidez superiores ao deste trabalho foram encontrados por MODOLON et al. (2012), ao analisarem qualidade pós-colheita de frutos de tomateiro, que obtiveram valores de acidez entre 0,38 e $0,43 \%$ e por RIBEIRO (2012), que ao avaliar a qualidade de tomates orgânicos e convencionais, obteve valores de 0,38 e 0,39\%, respectivamente, mostrando-se superiores aos encontrados neste trabalho para tomates orgânicos e, relativamente iguais para tomate convencional. SANTOS NETO et al. (2016), entretanto, encontraram resultados similares ao deste trabalho com frutos de tomateiro orgânico apresentando 0,25 e $0,31 \%$ de acidez.

Com relação ao $\mathrm{pH}$, a média geral dos tratamentos foi de 4,46 . Para esse parâmetro os tratamentos não diferiam $(p>0,05)$ entre si. Resultados intermediários aos encontrados por SOUSA et al. (2011), ao avaliarem as características físicas e químicas de frutos de diferentes acessos de tomateiro nas condições de casa de vegetação obtiveram médias de 4,28 a 5,08 respectivamente e NASCIMENTO et al. (2013) avaliando dez cultivares orgânicas de tomate de mesa encontraram valores de 4,22 a 4,44. OLIVEIRA et al. (2015) verificando rendimento de duas variedades de mesa alcançaram 4,36 e 4,42 .

Esses resultados mostram que o pH é um parâmetro que possui baixa estabilidade, independente da forma de cultivo seja orgânico ou convencional. Nos sólidos solúveis totais (SST), estão os principais componentes que dão o sabor ao fruto do tomateiro e que influenciam na escolha do consumidor e no rendimento industrial e é representado pelo Brix (GIORDANO et al., 2000).

Para os valores de SST o tomate convencional apresentou valor superior (4,75 Brix) em relação aos demais tratamentos. Tod avia entre os tratamentos orgânicos, não foi observada diferença estatística com valores médios de 3,77 a 3,92 Brix, corroborando que teor de sólidos solúve is no fruto além de ser uma característica genética, é influenciado pela adubação, temperatura e irrigação (NASCIMENTO et al.,2013). Resultado diferente foi obtido por RIBEIRO (2012), que observou que valores de SST não diferiram, obtendo-se 5,00 Brix para ambos os cultivos, convencional e orgânico; GOMES et al. (2012), trabalhando com tomate orgânico em monocultivo, obtiveram 4,08 Brix, apro ximando-se mais dos resultados deste trabalho.

O maior teor de sólidos solúveis na testemunha provavelmente foi efeito da adubação nitrogenada, pois o nitrogênio influencia diretamente na biossíntese de açúcares nas folhas e que posteriormente são translocados para os frutos, aumentando assim o teor de sólidos solúveis nos frutos convencionais. Obtendo-se o teor de sólidos solúveis (SS) e a acidez titulável (AT) foi estabelecida à relação SS/AT. Neste ensaio os tratamentos orgânicos demonstraram valores entre 15,70 e 17,27 , não diferindo $(p>0,05)$ entre si, entretanto, a testemunha resultou em valor inferior $(12,42)$ em relação aos demais tratamentos.

ROSA et al. (2011) analisando acessos de tomate italiano em sistema orgânico mostraram resultados similares ao deste trabalho entre 12,7 e 19,2. SANTOS NETO et al. (2016) avaliando a qualidade de frutos de tomateiro encontraram relação SS/AT superior aos tratamentos orgânicos em detrimento dos frutos sob manejo convencional com variação de 11,4 -16,09, contudo valores inferiores aos valores expostos neste trabalho bem como SCHWARZ et al. (2013) que encontraram valores médios entre 10,6 e 12,6. Conforme KADER et al. (1978), os frutos de alta qualidade possuem relação SS/AT maior que 10. Diante dos 
resultados pode se inferir que os frutos analisados, sobretudo os tomates orgânicos possuem boa qualidade.

\section{CONCLUSÕES}

Os tomates produzidos em manejo orgânico apresentaram padrões de qualidade para o consumo in natura. O tomate convencional apesar da elevada acidez em relação ao tomate orgânico, manteve o sabor aceitável para consumo à mesa haja vista ter apresentado maior teor de sólidos solúveis totais. Os cinco tratamentos orgânicos mostraram homogeneidade quanto às características físicas e físico-químicas analisadas.

\section{REFERÊNCIAS}

ALVARENGA, M. A. R. Tomate: produção em campo, casa de vegetação e hidroponia. Lavras: Editora UFLA,400p, 2004.

ALVARENGA, M. A. R. Tomate: produção em campo, casa de vegetação e hidroponia. 2.edição. Lavras: Editora Universitária de Lavras, 2013.

ASSOCIATION OF OFFICIALANALYTICAL CHEMISTRY. Official Methods of Analysis of the Association of Official Analytical Chemistry. 15 th. 33E. Washington, 1995. 2v.

BASTOS, E. A.; NUNES, B. H.; ANDRADE JUNIOR, A. S. Dados meteorológicos para o município de Parnaíba, PI. Teresina: Embrapa, 2000. 27p. (Documentos, 46).

BRASIL. Ministério da Saúde. Agência Nacional de Vigilância Sanitária. Métodos físico-químicos para análise de alimentos, 1018p., 2005.

BRITO JUNIOR, F. P. de. Produção de tomate (Solanum lycopersicum L.) reutilizando substratos sob cultivo protegido no município de Iranduba-AM. Dissertação (mestrado em produção vegetal). 2012, 61p.Universidade Federal do Amazonas, Manaus, 2012.

CHITARRA M. I. F; CHITARRA A. B. 2005. Pós-colheita de frutos e hortaliças: fisiologia e manuseio. Lavras: UFLA, 320p.

FAGUNDES, G. R., YAMANISHI, O. K. Características físicas e químicas de frutos do mamoeiro do grupo "Solo" comercializados em quatro estabelecimentos de Brasília-DF. Revista Brasileira de Fruticultura, v. 23, n. 3, p. 541-545, dezembro 2001.Disponível em:< http://www.scielo.br/scielo.php?script=sci_arttext\&pid=S010029452001000300018>. Acesso em: 10 de novembro de 2016.

FERREIRA, R. M. A.; LOPES, W. A. R.; AROUCHA, E. M. M.; MANO, N. C. S.; SOUSA, C. M. G. Caracterização física e química de híbridos de tomate em diferentes estádios de maturação produzidos em Baraúna, Rio Grande do Norte. Revista Ceres, Viçosa, v. 59, n.4, p. 506-511, jul/ago, 2012. Disponível em:< http://www.scielo.br/pdf/rceres/v59n4/11.pdf>. Acesso em: 3 de outubro de 2016. 
GIORDANO, L. B.; SILVA, J. B. C. da; BARBOSA, V. Escolha de cultivares e plantio. In: SILVA, J. B. C. da; GIORDANO, L. B. (Ed.) Tomate para processamento industrial. Brasília: EMBRAPA, 2000. p. 36-59.

GOMES F. B.; FORTUNATO L. J.; PACHECO A. L. V.; AZEVEDO L. H.; FREITAS N.; HOMMA S. K. 2012. Incidência de pragas e desempenho produtivo de tomateiro orgânico em monocultivo e policultivo. Horticultura Brasileira 30: 756-761.2012.

GONÇALVES, N. B. Qualidade de tomates cultivados em sistema orgânico e armazenados em temperatura ambiente e refrigerada / Neide Botrel Gonçalves [et al...]. -- Brasília : Embrapa Hortaliças, 2010.

INSTITUTO ADOLFO LUTZ. Normas analíticas, métodos químicos e físicos para análise de alimentos. São Paulo, 1985.

KADER A. A.; MORRIS, M. A.; STEVENS, M. A.; ALBRIGHT-HOLTON, M. Composition and flavor quality of fresh market as influenced by some postharvest handling procedures. Journal of the American Society for Horticultural Science, Alexandria, v. 103, n. 1, p. 6-11, 1978.

LEAL, M. A. de A. Produção de tomate orgânico: sistema PESAGRO-RIO. Niterói: PESAGRO-RIO, 2006. 39 p (PESAGRO-RIO Documentos, 97).

MACHADO NETO, A. da S. Viabilidade agroeconômica da produção de tomate de 'mesa' sob diferentes sistemas de cultivo e manejo de adubação. 2014,107f. Tese (Doutorado em Produção Vegetal) - Universidade Estadual do Norte Fluminense Darcy Ribeiro, Rio de Janeiro, 2014.

MODOLON TA; BOFF P; ROSA JM; SOUSA PMR; MIQUELLUTI DJ. 2012. Qualidade pós-colheita de frutos de tomateiro submetidos a preparados em altas diluições. Horticultura Brasileira v. 30, n. 1, jan. - mar. 2012. Disponível em:<http://www.scielo.br/pdf/hb/v30n1/v30n1a10.pdf>. Acesso em: 3 de outubro de 2016.

NASCIMENTO, A.R; SOARES JÚNIOR MS; CALIARI M; FERNANDES PM; RODRIGUES JPM; CARVALHO WT. 2013. Qualidade de tomates de mesa cultivados em sistema orgânico e convencional no estado de Goiás. Horticultura Brasileira 31: 628-635. Disponível em: <http://www.scielo.br/pdf/hb/v31n4/20.pdf>. Acesso em: 28 de setembro de 2016.

OLIVEIRA, P.R; TOMÉ, P. H. F; FRAGIORGE, E.J; LOPES, M. A; JESUS, E. J. Análises de variedades de tomates (Lycopersicum esculentum MILL) cv. Débora e Saladete na elaboração de catchup. Revista Científica Semana Acadêmica, n. 000069, 2015. Disponível em: <http://semanaacademica.org.br/artigo/analises-devariedades-de-tomates-lycopersicon-esculentum-mill-cv-debora-e-saladete-na>. Acesso em: 10 de novembro de 2016.

PAULA, J.T; RESENDE J. T. V; FARIA M.V; FIGUEIREDO, A. S.T; SCHWARZ K; NEUMANN, E. R. 2015. Características físico-químicas e compostos bioativos em 
frutos de tomateiro colhidos em diferentes estádios de maturação. Revista Horticultura Brasileira v.33 p.434-440. <http://dx.doi.org/10.1590/S0102053620150000400005 >. doi: 10.1590/S0102- 053620150000400005

PEIXOTO, J. R.; OLIVEIRA, C. M.; SILVA, R. P.; ANGELIS, B.; FILHO, A. B. C. Avaliação de genótipos de tomateiro tipo Santa Cruz no período de inverno, em Araguari, MG. Pesquisa Agropecuária Brasileira. Brasília, v.34, n.12, p.2247-2251, dez. 1999. Disponível em: <http://www.scielo.br/pdf/pab/v34n12/6928.pdf>. Acesso em: 30 de setembro de 2016 .

RIBEIRO, M. C. B. Qualidade de tomates orgânicos e convencionais amadurecidos na planta e após a colheita/ Marisa carvalho Botelho Ribeiro. Lavras: UFLA, 2012.

ROCHA, C. B. e SILVA, J. Atividade antioxidante total em tomates produzidos por cultivos orgânico e convencional. Brazilian Journal of Food Technology, Campinas, v. 14, n. 1, p. 27-30, jan./mar. 2011. Disponível em:< http://dx.doi: 10.4260/BJFT2011140100004>. doi: 10.4260/BJFT2011140100004

ROSA, C. L. S.; SOARES, A. G.; FREITAS, D. G. C.; ROCHA, M. C.; FERREIRA, J. C. S.; GODOY, R. L. O. Caracterização físico-química, nutricional e instrumental de quatro acessos de tomate italiano (Lycopersicum esculentum Mill) do tipo 'Heirloom' produzido sob manejo orgânico para elaboração de polpa concentrada. Alimentos Nutrição, Araraquara, v. 22, n. 4, p. 649-656, out./dez. 2011. Disponível em:< http://serv-bib.fcfar.unesp.br/seer/index.php/alimentos/article/viewFile/1640/1162 >. Acesso em: 28 de setembro de 2016.

SANTOS NETO, J. dos.; SCHWAN-ESTRADA, K. R. F.; SENA, J. O. A. de; JARDINETTI,V. do A.; ALENCAR, M. dos S. R.Qualidade de frutos de tomateiro cultivado em sistema de produção orgânico e tratados com subprodutos de capim limão. Revista Ciência Agronômica, v. 47, n. 4, p. 633-642, out-dez, 2016. Disponível em: <http://dx.doi:10.5935/1806-6690.20160076>.doi:10.5935/18066690.20160076 .

SCHWARZ K; RESENDE JTV; PRECZENHAK AP; PAULA JT; FARIA MV; DIAS DM. 2013. Desempenho agronômico e qualidade físico-química de híbridos de tomateiro em cultivo rasteiro. Revista Horticultura Brasileira v.31, n.3, p. 410-418, 2013. Disponível em:<http://tudosobretomate.com.br/index. php/tomate/14-artigoscat/131-horticultura-brasileira>. Acesso em: 10 de novembro de 2016.

SILVA, F. de A. S. e. AZEVEDO, C. A. V. de. Versão do programa computacional Assistat para o sistema operacional Windows. Revista Brasileira de Produtos Agroindustriais, Campina grande, v. 4, n. 1, p.71-78, 2002.

SOUSA, A. de A.; GRIGIO, M. L. ; NASCIMENTO, C. R. do.; SILVA, A. da C. D. da.; REGO, E. R. do.; REGO, M. M. do. Caracterização química e física de frutos de diferentes acessos de tomateiro em casa de vegetação. Revista Agro@mbiente On-line, v. 5, n. 2, p.113-118, maio-agosto, 2011. Disponível em: 
<http://revista.ufrr.br/agroambiente/article/view/534> . Acesso em: 3 de outubro de 2016.

STROHECKER, R.; HENNING, H. M. Analisis de vitaminas: métodos comprobados. Madrid: Paz Montalvo, 1967. 428 p. 